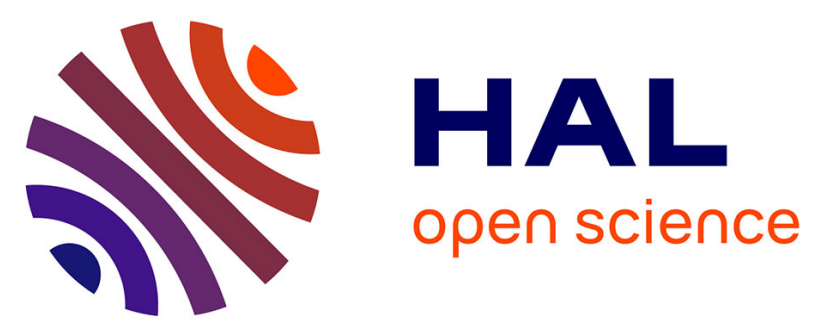

\title{
Rosiglitazone Balances Insulin-Induced Exo- And Endocytosis In Single 3t3-L1 Adipocytes
}

\author{
Jelena Velebit, Helena H. Chowdhury, Marko Kreft, Robert Zorec
}

\section{To cite this version:}

Jelena Velebit, Helena H. Chowdhury, Marko Kreft, Robert Zorec. Rosiglitazone Balances InsulinInduced Exo- And Endocytosis In Single 3t3-L1 Adipocytes. Molecular and Cellular Endocrinology, 2011, 333 (1), pp.70. 10.1016/j.mce.2010.12.014 . hal-00660888

\section{HAL Id: hal-00660888 https://hal.science/hal-00660888}

Submitted on 18 Jan 2012

HAL is a multi-disciplinary open access archive for the deposit and dissemination of scientific research documents, whether they are published or not. The documents may come from teaching and research institutions in France or abroad, or from public or private research centers.
L'archive ouverte pluridisciplinaire HAL, est destinée au dépôt et à la diffusion de documents scientifiques de niveau recherche, publiés ou non, émanant des établissements d'enseignement et de recherche français ou étrangers, des laboratoires publics ou privés. 


\section{Accepted Manuscript}

Title: Rosiglitazone Balances Insulin-Induced Exo- And Endocytosis In Single 3t3-L1 Adipocytes

Authors: Jelena Velebit, Helena H. Chowdhury, Marko Kreft, Robert Zorec



PII:

S0303-7207(10)00577-0

DOI: doi:10.1016/j.mce.2010.12.014

Reference: MCE 7719

To appear in: Molecular and Cellular Endocrinology

Received date: $11-10-2010$

Revised date: 6-12-2010

Accepted date: $7-12-2010$

Please cite this article as: Velebit, J., Chowdhury, H.H., Kreft, M., Zorec, R., Rosiglitazone Balances Insulin-Induced Exo- And Endocytosis In Single 3t3-L1 Adipocytes, Molecular and Cellular Endocrinology (2010), doi:10.1016/j.mce.2010.12.014

This is a PDF file of an unedited manuscript that has been accepted for publication. As a service to our customers we are providing this early version of the manuscript. The manuscript will undergo copyediting, typesetting, and review of the resulting proof before it is published in its final form. Please note that during the production process errors may be discovered which could affect the content, and all legal disclaimers that apply to the journal pertain. 


\section{ROSIGLITAZONE BALANCES INSULIN-INDUCED EXO- AND ENDOCYTOSIS IN SINGLE 3T3-L1}

\section{ADIPOCYTES}

Jelena Velebit, ${ }^{a}$ Helena H. Chowdhury, ${ }^{\text {a, }}{ }^{\text {Marko Kreft, }}{ }^{\text {a, b }}$ and Robert Zorec ${ }^{\text {a, b,* }}$

${ }^{a}$ Celica, Biomedical Center, Technology Park 24, 1000 Ljubljana, Slovenia; and

${ }^{\mathrm{b}}$ Laboratory for Neuroendocrinology - Molecular Cell Physiology, Institute of Pathophysiology, Faculty of Medicine, University of Ljubljana, Zaloska 4, 1000 Ljubljana, Slovenia

*Correspondening author at: Laboratory for Neuroendocrinology - Molecular Cell Physiology, Institute of Pathophysiology, Faculty of Medicine, University of Ljubljana, Zaloska 4, 1000 Ljubljana, Slovenia.

Tel: +3861 5437080; Fax: +38615437036.

E-mail address: robert.zorec@mf.uni-lj.si (R. Zorec). 


\begin{abstract}
Rosiglitazone (Rosi) improves insulin sensitivity and increases the translocation of glucose transporter 4 (GLUT4) to the plasma membrane (PM). This involves the fusion of membranebound compartments with the plasma membrane, thus increasing the plasma membrane area. However, recent work has shown that in Rosi-pretreated 3T3-L1 adipocytes membrane area did not increase following insulin application, suggesting that the rates of exo- and endocytosis are balanced. Here we examined whether Rosi differentially affects the rates of exo- and endocytosis in 3T3-L1 adipocytes. The immunolabelling of GLUT4 revealed the 3.1-fold increase in PM-resident GLUT4 in Rosi-pretreated, insulin-stimulated cells. By monitoring cumulative exocytosis and endocytosis we found that in Rosi-pretreated cells insulin substantially stimulated the rate of exocytosis and to a similar extent also the rate of endocytosis. We conclude that Rosi-pretreatment balances insulin-stimulated exocytosis and endocytosis, which may prevent insulin-mediated adipocyte cell size increase.
\end{abstract}

Keywords: Adipocytes, GLUT4, Rosiglitazone, Exocytosis, Endocytosis, Insulin 


\section{Introduction}

The rate of glucose uptake in muscle and adipose tissue is limited by the density of the glucose transport proteins on the plasma membrane (Bryant et al., 2002; Foster and Klip, 2000). Insulin regulates glucose uptake in adipocytes and muscle cells by controlling the subcellular distribution of glucose transporters GLUT4 (Holman and Sandoval, 2001; Muretta et al., 2008). In the basal conditions, GLUT4 is largely excluded from the plasma membrane and is retained within endosomes, the trans-Golgi network, and tubular-vesicular compartments termed GLUT4 storage vesicles (GSVs) (Bryant et al., 2002; Foster and Klip, 2000). Insulin triggers the redistribution of GLUT4 from intracellular compartments to the plasma membrane which increases the membrane glucose permeability (Muretta et al., 2008). This appears to be associated with a plasma membrane area increase (Chowdhury et al., 2005; Velebit et al., 2008). When insulin is removed, GLUT4 is rapidly cleared from the plasma membrane back into intracellular compartments (Muretta et al., 2008). Thus the distribution of GLUT4 is controlled by insulin-mediated effects on the rate of exo- and endocytosis (Muretta et al., 2008).

Insulin resistance is characterized by a reduced ability of major insulin target tissues such as skeletal muscle, adipose tissue and liver to respond to the action of insulin (Petersen and Shulman, 2002; Rattarasarn, 2006; Toledo et al., 2006). Thiazolidinediones (TZD) represent a class of oral hypoglycaemic agents that have been shown to improve insulin action and reverse some of the metabolic processes responsible for the development of insulin resistance and, finally, type 2 diabetes in predisposed subjects (Bhatia and Viswanathan, 2006; Mudaliar and Henry, 2001). Systemically, TZDs lower hyperglycaemia by increasing peripheral glucose utilization and decreasing hepatic glucose production in human and in experimental models of insulin resistance (Bhatia and Viswanathan, 2006; Olefsky, 2000). At cellular level the insulin sensitizing effects of TZDs are mediated through 
the peroxisome proliferator-activated receptor $\gamma(\operatorname{PPAR} \gamma)$ (Bhatia and Viswanathan, 2006) which is highly abundant in adipose tissue and to a lesser extent in skeletal muscle and liver (Auwerx, 1999; Olefsky, 2000). A representative of TZD, rosiglitazone (Rosi), is a potent agonist of PPAR $\gamma$ and improves the differentiation of 3T3-L1 cells into adipocytes (Rangwala and Lazar, 2004; Velebit et al., 2008). Furthermore, adipocyte differentiation leads to the enhanced expression of adipocyte-specific genes, such as GLUT4 and insulin receptor substrate-1 (IRS-1), which are important components of the insulin receptor signaltransduction pathway (Ntambi and Young-Chuel, 2000; Okuno et al., 1998; White and Kahn, 1994; Wu et al., 1998). It was shown that the treatment of 3T3-L1 adipocytes with Rosi during differentiation results in the accumulation of GLUT4 at the plasma membrane surface (Martinez et al., 2010), which is consistent with the concept that TZDs regulate membrane dynamics (Velebit et al., 2008). However, the mechanism by which Rosi affects the increased density of GLUT4 at the plasma membrane remains unclear. It has been shown that insulin induces an increase in net changes of plasma membrane surface area of single 3T3-L1 cells by increasing the rate of exocytosis, via phosphatidylinositol 3-kinase, as in the case of insulin-induced GLUT4 translocation (Velebit et al., 2008), consistent with insulin-induced surface area measurements in adipocytes (Chowdhury et al., 2002, 2005). Interestingly, the pretreatment of 3T3-L1 cells with Rosi significantly attenuated the insulin-induced increase in membrane area (Velebit et al., 2008), which could be due to a simultaneous insulininduced increase in exo- and endocytosis of Rosi-pretreated cells. To directly address this, we here employed quantitative confocal microscopy and the styryl fluorescent dye FM1-43, a membrane area marker (Cochilla et al., 1999) to monitor cumulative exocytosis as well as cumulative endocytosis of single 3T3-L1 adipocytes pretreated with Rosi and stimulated with insulin. We also examined subcellular localization of GLUT4 in 3T3-L1 cells by 
immunocytochemistry. The physiological significance of our results is discussed in the context of adipocyte cell size regulation. 


\section{Materials and methods}

\subsection{Chemicals}

Dulbecco's modified Eagle's medium (DMEM), Calf serum (CS), dexamethasone, isobutylmethylxanthine (IBMX), $N$-2-hydroxyethylpiperazine- $N$ '-2-ethanesulfonic acid (HEPES), KCl, D-glucose, $\mathrm{NaH}_{2} \mathrm{PO}_{4}, \mathrm{NaHCO}_{3}, \mathrm{Na}_{2} \mathrm{ATP}$, phosphate buffered saline (PBS), bovine serum albumin (BSA), goat serum, paraformaldehyde, triton X-100 and insulin were purchased from Sigma (St. Louis, $\mathrm{MO}$ ). $\mathrm{CaCl}_{2} \times 6 \mathrm{H}_{2} \mathrm{O}$ was obtained from Riedel De Haen (Seelze-Hannover, Germany). $\mathrm{MgCl}_{2}$ was purchased from Kemika (Zagreb, Croatia). Rosiglitazone maleate was obtained from GlaxoSmithKline (Worthing, UK). Dimethyl sulfoxide (DMSO) was purchased from Merck Schuchardt (Hohenbrunn, Germany). AntiGLUT4 rabbit polyclonal antibody was obtained from Abcam (Cambridge, UK) and goat anti-rabbit IgG antibody was obtained from Molecular Probes. Vehicle solution contained 1\% acidic acid.

\subsection{Cell Culture}

3T3-L1 fibroblasts were grown in DMEM containing $10 \% \mathrm{CS}$, as described previously (Rangwala and Lazar, 2004). Briefly, fibroblasts were seeded onto poly-L-lysinecoated coverslips and allowed to grow to confluence. Conversion into adipocytes was induced on day 0 in DMEM containing $10 \% \mathrm{CS}$, $0.25 \mathrm{mM}$ dexamethasone, $0.5 \mathrm{mM}$ IBMX and $174 \mathrm{nM}$ insulin for 2 days (time zero to day 2), and then medium was replaced with DMEM containing $10 \% \mathrm{CS}$ and $174 \mathrm{nM}$ insulin for a further 2 days (days 2-4). On day 6 most of the cells were differentiated and cells were transferred to DMEM containing $10 \%$ CS. During experiments, rosiglitazone was added to a final concentration of $10 \mu \mathrm{M}$, from a 1 $\mathrm{mM}$ stock prepared in DMSO. Insulin was prepared as a $1.74 \mathrm{mM}$ stock solution in acidified 
$\mathrm{H}_{2} \mathrm{O}(\mathrm{pH} 2$, using glacial acetic acid, approx. $1 \%$ ). Differentiated 3T3-L1 cells were divided into four experimental groups for each type of experiments: (1) control cells, vehicle addition (+Veh); (2) cells stimulated with $0.2 \mu \mathrm{M}$ insulin for $6 \mathrm{~min}(+\mathrm{Ins})$; (3) cells pretreated with 10 $\mu \mathrm{M}$ rosiglitazone for $24 \mathrm{~h}(\mathrm{Rosi}+\mathrm{Veh})$, and then treated with vehicle and (4) cells pretreated with $10 \mu \mathrm{M}$ rosiglitazone for $24 \mathrm{~h}$ and then stimulated with $0.2 \mu \mathrm{M}$ insulin for an additional 6 $\min ($ Rosi + Ins)

\subsection{Immunofluorescence}

To identify the expression of GLUT4 on the adipocytes surface, the primary rabbit anti-GLUT4 antibodies (Abcam, Cambridge, UK) were used and secondary goat anti-rabbit antibody conjugated to fluorescent dye Alexa Fluor 546 (Molecular Probes). 3T3-L1 cells were washed with PBS, fixed in $4 \%$ paraformaldehyde in PBS for $15 \mathrm{~min}$, and then incubated in $0.1 \%$ Triton $\mathrm{X}-100$ for $10 \mathrm{~min}$ at room temperature. Non-specific staining was reduced by incubating cells in blocking buffer containing $3 \% \mathrm{BSA}$ and $10 \%$ goat serum in $\mathrm{PBS}$ at $37^{\circ} \mathrm{C}$ for $1 \mathrm{~h}$. The cells were incubated with primary antibody (diluted 1:100) in $3 \%$ BSA in PBS at $37^{\circ} \mathrm{C}$ for 2 hours and secondary antibody (diluted 1:600) in $3 \%$ BSA in PBS for 45 min at $37^{\circ} \mathrm{C}$. Subsequently, they were mounted using the Light Antifade kit (Invitrogen). Z-stacks were acquired for each immuno-labelled cell detected using a Zeiss LSM 510 confocal microscope through a planapochromatic oil-immersion objective (x 63, NA=1.4), excited by the $543 \mathrm{~nm} \mathrm{He} / \mathrm{Ne}$ laser line and filtered with the $560 \mathrm{~nm}$ low-pass emission filter. Images were quantitatively analyzed using custom software written in Matlab programming language (Math Works, Natick, MA). Eight to 15 markers were manually set to the cell perimeter, and the software interpolated the curve between the markers. The software eroded pixels from the marked perimeter curve to obtain $1.1 \mu \mathrm{m}$ wide zone around the plasma membrane. This procedure resulted in two separated regions of each confocal image: cell periphery and the 
cell interior. The mean fluorescence intensity of these regions was calculated and then the ratio of fluorescence intensity between plasma membrane area and cytoplasm $\left(\mathrm{I}_{\mathrm{m}} / \mathrm{I}_{\mathrm{c}}\right)$ was determined.

\subsection{Time-laps confocal microscopy and fluorimetry}

Differentiated 3T3-L1 adipocytes were placed in a recording chamber on the confocal microscope (LSM 510, Zeiss, Oberkochen, Germany). The recording medium consisted of (in $\mathrm{mM}$ ): $\mathrm{NaCl} 131.8, \mathrm{CaCl}_{2} 1.8, \mathrm{KCl} 5, \mathrm{MgCl}_{2}$ 2, HEPES/NaOH 10, D-glucose 10, $\mathrm{NaH}_{2} \mathrm{PO}_{4}$ 0.5, $\mathrm{NaHCO}_{3} 5 ; \mathrm{pH}$ 7.2. The recording medium also contained $4 \mu \mathrm{M}$ FM1-43 (Molecular Probes, Eugene, Ore., USA), diluted previously in DMSO to obtain a $1 \mathrm{mM}$ stock.

FM1-43 is an amphiphilic styryl dye that has been used extensively to monitor individual exocytic and endocytic events, as well as vesicle membrane cycling in a variety of cell types, including neuroendocrine cells (Cochilla, 1999) and adipocytes (Chowdhury, 2002). From the extracellular fluid these dye molecules reversibly partition into the outer leaflet of surface membrane, but they can not penetrate to the cytoplasm, owing to their charged head groups (Henkel, 1996). During exocytosis the luminal vesicle membrane become exposed to external medium and gets stained with FM1-43, thus contributing to the increase in the FM1-43 fluorescence intensity and to the increase in the plasma membrane area. Simultaneously, fluorescently stained membranes get internalized via endocytosis, hence the entire cell fluorescence intensity increase persists and the steady increase in fluorescence signal provides a cumulative record of exocytosis (Neves and Lagnado, 1999). After removal of FM1-43 from the medium, dye molecules dissociate from the membrane to the extracellular medium, causing the plasma membrane to destain (Henkel, 1996). However cells retain residual fluorescence because some of dye-labeled membrane is internalized by endocytosis. If a stained endosome undergoes exocytosis in dye-free medium, then dye 
molecules dissociate from this membrane (Henkel, 1996). Thus changes in FM1-43 fluorescence intensity are an index of changes in plasma membrane area (Betz, 1996). Because GLUT4 is stored in the membrane of GLUT4 storage vesicles (GSV; Zorzano, 1989) and insulin induces the GSV translocation to- and fusion with the plasma membrane of adipocytes (Smith, 1991), this event is inseparably bound to the increase of the plasma membrane area.

To study exocytosis, cells were exposed to FM1-43 for 3-5 min before the addition of insulin. After addition of FM1-43 to the recording medium the final concentration of DMSO was less than $0.5 \%$. During experiments we added insulin (final concentration $0.2 \mu \mathrm{M}$ ) or vehicle, respectively. Images were scanned for $10 \mathrm{~min}$ with a $20 \mathrm{~s}$ scan interval and analysed quantitatively using the LSM 510 (Time series software, Carl Zeiss). The effect of insulin and vehicle addition onto cells was quantified by measuring changes in FM1-43 fluorescence intensity of entire cell image relative to the resting levels (fluorescence intensity at the time of insulin addition) every $60 \mathrm{~s}$ after stimulation.

To establish whether insulin stimulates endocytosis in control and Rosi-pretreated cells, we exposed cells to the following protocol (see Fig. 4A): cells were exposed to FM1-43 fluorescent dye for 1 minute to establish a baseline for individual cell. After that FM1-43 dye was washed out from the recording chamber and replaced with extracellular solution for 5 minutes. Cells were then stimulated with insulin and incubated again with FM1-43 for 6 minutes and again washed out. After removal of FM1-43, cells retained a residual fluorescence, because FM1-43 dye was internalized by endocytosis. After both FM1-43 washouts z-stacked images of cells were acquired. The effect of insulin and vehicle addition onto cells was quantified by measuring changes in FM1-43 residual fluorescence intensity of the cell interior after second incubation relative to the residual fluorescence of cell interior after first incubation with FM1-43. 
The fluorescence images of FM1-43 stained cells were acquired through a planapochromatic oil-immersion objective $(\mathrm{x} 40, \mathrm{NA}=1.3)$, excited by the $488 \mathrm{~nm}$ argon laser line and filtered with the $505 \mathrm{~nm}$ low-pass emission filter. All experiments were performed at room temperature. Data are given as mean \pm SEM. 


\section{Results}

3.1. Immuno-labelling reveals that rosiglitazone-pretreatment of 3T3-L1 cells increases the insulin-induced GLUT4 translocation to the plasma membrane

To determine whether subcellular distribution of GLUT4 is modulated by rosiglitazone (Rosi), we performed GLUT4 immuno-labelling in single 3T3-L1 cells (Fig. 1A), as addressed previously (Martinez et al., 2010). Cells were pretreated with $10 \mu \mathrm{M}$ Rosi for $24 \mathrm{~h}$ and then stimulated with $0.2 \mu \mathrm{M}$ Ins (Fig. 1A, Rosi + Ins) or with vehicle only (Fig. 1A, Rosi) for 6 minutes. Insulin stimulated cells (Fig. 1A, +Ins) were used to test whether these cells exhibit GLUT4 translocation from the cytoplasm to the plasma membrane in comparison to non-stimulated conditions (Fig. 1A, +Veh).

Figure 1.

Fluorescence labelling with anti-GLUT4 antibody (see Materials and Methods) revealed the presence of GLUT4 in the cytoplasm and in the plasma membrane of 3T3-L1 adipocytes (Fig. 1A), as previously reported (Martinez et al., 2010). To measure the extent of translocation of GLUT4 between the cytoplasm and the plasma membrane, we determined the ratio of fluorescence intensity at the plasma membrane region vs. that of the cytoplasm (Fig. 1B, see Materials and Methods). The ratio of fluorescence intensity in Ins-stimulated cells was $2.1 \pm 0.1(\mathrm{n}=12)$, significantly higher than in control cells to which only the vehicle was applied $1.0 \pm 0.1(\mathrm{n}=16, \mathrm{P}<0.001$; Fig. 1B). Interestingly, the pretreatment of cells with Rosi also resulted in a higher ratio of fluorescence intensity compared to control cells $(2.0 \pm$ $0.2, \mathrm{n}=9 ; \mathrm{p}<0.001$ ), however not significantly different than in Ins-treated cells (Fig 1B), consistent with data on cell populations (Martinez et al., 2010). The ratio of fluorescence 
intensity of the (Rosi+Ins)-(pre)treated cells was $3.1 \pm 0.2(\mathrm{n}=8)$, significantly higher than in control cells $(\mathrm{P}<0.001)$ and also higher than in only Rosi-pretreated $(\mathrm{P}<0.01)$ or only Insstimulated cells $(\mathrm{P}<0.01)$. These results on single cells show that Rosi, Ins and Rosi+Ins (pre)treatments increase the fraction of GLUT4 at the plasma membrane vs. the cytoplasm and that the effects of Rosi and insulin are additive.

\subsection{Rosiglitazone Augments Insulin-Induced Increase in FM1-43 Fluorescence Reporting}

\section{Cumulative Exocytosis}

To study the rate of exocytosis in single cells, we measured the changes in FM1-43 fluorescence intensity of single cell relative to the value at the time of Ins or Veh addition (Fig 2A). Once 3T3-L1 cells were placed into the recording medium, we started to scan cells with the argon laser to determine the resting fluorescence. To establish whether Ins addition stimulates membrane dynamics, we added a bolus into the chamber (see Materials and methods) to reach a final concentration of $0.2 \mu \mathrm{M}$ Ins with non-pretreated and Rosipretreated cells, respectively. In controls we applied the Veh only. Fluorescent images on Figure 2A show live 3T3-L1 adipocytes, before (left images) and after (right images) vehicle $(+\mathrm{Veh})$ or insulin (+Ins) additions to non-pretreated cells and to Rosi-pretreated cells (Rosi+Veh and Rosi+Ins). In the presence of Ins, the fluorescence intensity at the cell perimeter increased significantly vs. controls (Fig. 2A, right), consistent with previous experiments on primary adipocytes (Chowdhury et al., 2002, 2005).

Figure 2.

The right hand on Fig. 2A shows representative recordings of time-dependent changes in fluorescence intensity. Upon the addition of $4 \mu \mathrm{M}$ FM1-43, fluorescence intensity of the 
cells increased and eventually attained a slow, steady increase of the fluorescence signal. Some of the dye is internalised by endocytosis, therefore we measured the fluorescence intensity of entire cell to obtain a report of cumulative exocytosis (Neves and Lagnado, 1999). In controls, the addition of Veh as a bolus resulted in a small change in the slope of the FM1-43 fluorescence intensity signal (+Veh). However, the application of Ins to nonpretreated cells augmented the rate of FM1-43 fluorescence intensity increase (+Ins), which is consistent with an increase in membrane area, as reported (Chowdhury et al., 2002; Velebit et al., 2008). Importantly, the rate of FM1-43 fluorescence intensity signal increased significantly in Rosi-pretreated cells vs. non-pretreated cells (Rosi+Veh), almost following the signal increase in Ins-stimulated cells. The application of Ins to Rosi-pretreated cells promoted further the increase in FM1-43 fluorescence intensity (Rosi+Ins) and was significantly higher than in only Ins-stimulated cells.

The results are summarized in Figure 2B. Mean changes in FM1-43 fluorescence intensity of entire cell intersection were calculated for every minute interval after application of the drug. With linear regression analysis of data points (dotted lines) we calculated the rate of FM1-43 fluorescence intensity increase. Regression lines are drawn according to the equation: $\mathbf{y}=\mathbf{a x}+\mathbf{n}$; where $\mathbf{y}$ is mean fluorescence intensity [\%], $\mathbf{a}$ is the slope coefficient $[\% / \mathrm{min}], \mathbf{x}$ is time [min] and $\mathbf{n}$ is resting fluorescence intensity [\%]. All slope coefficients are significantly different from zero $(\mathrm{p}<0.001)$ and report change in the fluorescence intensity per unit of time, which reflects the rate of cumulative exocytosis. In controls, following the application of Veh, FM1-43 fluorescence increased by $11.7 \pm 1.6 \%$ in 6 min, with a slow steady rate of $1.8 \pm 0.1 \% / \min$ (Fig $2 \mathrm{~B}$ i, open circles, $\mathrm{n}=6$ ), as evidenced by the regression analysis. In Rosi-pretreated cells the fluorescence intensity increased by $31.4 \pm 5.9 \%$ (6 min after the vehicle addition) and corresponding regression line revealed a steady increase with a slope coefficient of $5.3 \pm 0.1 \% / \mathrm{min}$ (Fig $2 \mathrm{~B}$ ii, open squares, $\mathrm{n}=6$ ), significantly higher from 
controls $(\mathrm{P}<0.001)$. Ins-application resulted in a fluorescence signal increase of $45.8 \pm 6.0 \%$ with the rate in fluorescence signal of $7.3 \pm 0.5 \% /$ min (Fig. $2 B$ i, full circles, $n=7$ ), significantly different from controls $(\mathrm{P}<0.001)$. Six minutes following the addition of Ins into the chamber with Rosi-pretreated cells, fluorescence intensity increased by $72.4 \pm 7.0 \%$ and the rate of fluorescence intensity increase, corresponding to a slope coefficient of the regression line, was $11.2 \pm 0.6 \% / \mathrm{min}$ (Fig. $2 \mathrm{~B}$ ii, full squares, $\mathrm{n}=6$ ), significantly higher than in controls $(\mathrm{P}<0.001)$, in Rosi-pretreated cells $(\mathrm{P}<0.001)$ and in cells stimulated with Ins only $(\mathrm{P}<0.001)$. These results are consistent with the view that the Rosi-pretreatment augments the Ins-induced increase in cumulative exocytosis in 3T3-L1 cells.

\subsection{Rosiglitazone pretreatment increases Cumulative Endocytosis}

In another set of experiments, we determined the rate of cumulative endocytosis in 3T3-L1 cells in basal and in stimulated conditions. After the wash of FM1-43 from the chamber medium, 3T3-L1 cells retained a residual fluorescence, indicating FM1-43 dye internalisation by endocytosis. Between the two FM1-43 exposures insulin or vehicle were added to the cells (Fig. 3A) and the \% change between both residual fluorescence was taken as the read out of the rate of cumulative endocytosis (in $\% / \mathrm{min}$ ). We compared the residual fluorescence intensity (a.u.) of cells following the two sequential exposures/removals of FM1-43 (Fig. 3B). After second incubation with FM1-43 dye the mean intensity of residual fluorescence significantly increased compared to first incubation in each group of cells (Fig. 3B), demonstrating a cumulative endocytosis. The results are summarized in Fig. 3C. In controls $(+$ Veh) the rate of cumulative endocytosis was $2.1 \pm 0.3 \% / \mathrm{min}(\mathrm{n}=7)$, whereas in Rosi-pretreated cells (Rosi+Veh) it was $4.5 \pm 0.7 \% / \min (n=7)$, significantly higher than in controls $(\mathrm{P}<0.01)$. The application of insulin $(+\mathrm{Ins})$ resulted in a significant increase in the rate of endocytosis compared to controls $(\mathrm{P}<0.01)$ and was $7.5 \pm 1.8 \% / \mathrm{min}(\mathrm{n}=4)$, however 
not significantly different than in Rosi-pretreated cells (Rosi+Veh). Importantly, in cells pretreated with $10 \mu \mathrm{M}$ Rosi for $24 \mathrm{~h}$, subsequent insulin application (Rosi+Ins) promoted the rate of endocytosis to $13.3 \pm 1.6 \% / \mathrm{min}(\mathrm{n}=4)$, which was significantly higher than in control cells, in Rosi-pretreated cells and in cells stimulated with Ins $(\mathrm{P}<0.01)$.

Figure 3.

Results and comparison of cumulative exo- and endocytosis measurements are summarized in Table 1. These results indicate that Ins and Rosi, when together, stimulate plasma membrane area dynamics via the enhancement of the rates of exocytosis and endocytosis to approximately the same extent. 


\section{Discussion}

In this study we examined the effects of insulin and rosiglitazone on the regulation of membrane area dynamics in single 3T3-L1 adipocytes. Specifically, we examined (1) the effect of Rosi-pretreatment on GLUT4 translocation to the plasma membrane by quantitative confocal microscopy, (2) the effect of Ins application on cumulative exocytosis and endocytosis and (3) the effect of acute $(24 \mathrm{~h})$ rosiglitazone pretreatment on Ins-mediated plasma membrane dynamics.

\subsection{Rosiglitazone increases the plasma membrane GLUT4 density via altered membrane} dynamics

Translocation of GLUT4 from intracellular pool to the plasma membrane involves insulin-induced exocytosis of GLUT4 bearing vesicles (Ezaki et al., 1986; Oka and Czech, 1984; Whitesell and Abumrad, 1985). Increased exocytosis is associated with an increase in plasma membrane surface area (Chowdhury et al., 2002, 2005; Velebit et al., 2008). Results in this study (Fig. 1) confirm that insulin stimulation increases the density of GLUT4 on the plasma membrane.

Rosi is a potent antidiabetic drug which improves insulin sensitivity and glycaemic status (Phillips et al., 2001). In addition, it was shown that pretreatment with Rosi and other TZDs leads to the reduction of the adipocyte cell size (Johnson et al., 2007; Velebit et al., 2008). This may be due to alterations in membrane dynamics; however, the mechanism of cell size reduction was not studied yet. Our results obtained at cellular level show that in 3T3L1 adipocytes the fraction of membrane GLUT4 is increased following the pretreatment with Rosi (Fig. 1A, Rosi+Veh), which is consistent with recently reported observations (Martinez et al., 2010). Moreover, the Rosi-pretreatment enhanced the Ins-induced fraction of GLUT4 
at the plasma membrane (Fig. 1B, Rosi+Ins), as was also shown in cell populations (Martinez et al., 2010). While it was suggested that the increased fraction of GLUT4 at the plasma membrane may be due to altered membrane dynamics (Velebit et al., 2008), and/or endosomal recycling (Martinez et al., 2010), this was not studied directly. The results on Figures 2 and 3 suggest that the increased localization of GLUT4 at the plasma membrane may be due to Rosi-mediated discrete effects on the rate of exo- and endocytosis, since Ins significantly increased the fluorescence intensity of the FM1-43 (Fig. 2A) and application of Rosi (24 h) amplified the effect of Ins.

A slow steady increase in FM1-43 fluorescence observed in resting cells (Fig. 2A) is likely due to constitutive exocytosis (Chowdhury et al., 2002). In support of membrane internalization after a continuous slow process of exocytosis, we observed that cells exposed to FM1-43 remained fluorescent even after removing FM1-43 from the medium (Fig. 3A). This indicates that some of the FM1-43 dye molecules are captured within cells by endocytosis.

\subsection{Rates of exocytosis and endocytosis after rosiglitazone and insulin treatment}

\subsubsection{The effect of insulin}

Here we show that insulin application increases the rate of exocytosis by a factor of 4.0 vs. controls (Table 1) in 3T3-L1 adipocytes, similar to the increase elicited by insulin in primary adipocytes (Chowdhury et al., 2002). This increase in rate of exocytosis is probably associated with GLUT4 density regulation (Czech, 2002) and/or secretion of e.g. adipsin, Acrp30 (Ahima and Flier, 2000; Kitagawa et al., 1989; Scherer et al., 1995) and other adipokines. An increased density of plasma membrane transporters by insulin (Figure 1), could also be due to an inhibition of endocytosis, but our results show that endocytosis is not inhibited by insulin. In contrast, insulin increased the rate of cumulative endocytosis by a 
factor of 3.6 vs. controls (Table 1). The insulin-mediated increased rate of endocytosis may be associated with the internalization of insulin and the insulin receptor (Di Guglielmo et al., 1998). However, since GLUT4 continuously cycles between vesicles and the plasma membrane (Saltiel and Kahn, 2001), it is conceivable that insulin increases cell surface density of the transporter not only by increasing the exocytotic rate but also by increasing the size of the recycling GLUT4 pool (Muretta et al., 2008), implicating a potential role for endocytosis in regulating cell surface levels of the transporter in adipocytes. Although the rates of exo- and endocytosis do not appear significantly different $(\mathrm{P}=0.73$; Table 1$)$, the fold increase compared to controls is greater in exocytosis, which is in accordance with our previously published data, where insulin was shown to stimulate plasma membrane area increase in 3T3-L1 adipocytes (Velebit et al., 2008).

\subsubsection{The effect of rosiglitazone}

Although it is generally thought that TZDs mediate their insulin-sensitizing effects via PPAR $\gamma, \operatorname{PPAR} \gamma$-independent pathways have also been suggested (Blackmore et al., 1993; Furnsinn et al., 1999; Preininger et al., 1999; Chawla et al., 2001).

Our results show that cells exposed to rosiglitazone for 24 hours exhibit an augmented rate in exocytosis (Fig. 2B), by a factor of 2.9 vs. controls (Table 1). We measured also an increase in the rate of endocytosis (Fig. 3C) by a factor of 2.2 vs. controls (Table 1). It seems that rosiglitazone augments constitutive exocytosis as well as constitutive endocytosis, thus consequently increases the membrane turnover, indicating altered adipocyte biology due to rosiglitazone action. It is possible that rosiglitazone selectively affects the synthesis of some molecules involved in the translocation of GLUT4, as it was demonstrated that in 3T3-L1 adipocytes a member of TZD family, troglitazone, increases the expression of annexin II, which is involved in vesicular transport (Huang et al., 2004). These and other molecules, 
which are implicated in exocytosis, may be involved in the increased translocation of GLUT4 in rosiglitazone-pretreated cells. Moreover, a recent study demonstrates that rosiglitazone induces an increase in the expression of the insulin receptor (Martinez et al., 2010), which could imply an activation of the insulin signalling cascade.

\subsubsection{Synergistic effect of rosiglitazone and insulin}

Rosiglitazone, a PPAR $\gamma$ agonist, intensifies insulin signalling in adipose tissue (Ahima and Flier, 2002), however it attenuates the insulin-stimulated increase in membrane surface area (Velebit et al., 2008). It was suggested that in rosiglitazone-pretreated cells insulin stimulates a rapid increase in exocytosis that is associated with a similar increase in the rate of endocytosis, since both processes appear to be controlled by insulin (Velebit et al., 2008). In the current study, the application of insulin in Rosi-pretreated cells (Rosi+Ins) stimulates a rapid increase in the rate of exocytosis by a factor of 6.1 vs. controls (+Veh) and by a factor of 1.5 vs. Rosi-nontreated cells (+Ins) (Table 1). These results indicate that rosiglitazone invigorates insulin-stimulated exocytosis. Insulin application in Rosi-pretreated cells also increased the residual fluorescence intensity, reporting cumulative endocytosis by a factor of 6.3 vs. controls (+Veh) and by a factor of 1.8 vs. Rosi-nontreated cells (+Ins). These results report that the insulin-stimulated endocytosis, as shown previously (Chowdhury et al., 2005), is highly amplified with rosiglitazone pretreatment. While the absolute rates of exo- and endocytosis are comparable (Table $1 ; \mathrm{P}=0.54$ ), the comparison of rates of exo- and endocytosis (Table 1) shows that Rosi-pretreatmet affected more strongly the insulin induced-increased rate of endocytosis (1.8 fold) than the rate of exocytosis ( 1.5 fold).

If the overall rates of exo- and endocytosis are linearly related to the dynamics of exoand endocytosis of vesicles bearing GLUT4 solely, then one would expect that rosiglitazone would not enhance the membrane resident fraction of GLUT4. In contrast, the data in Figure 
1 indicate that the dynamics of GLUT 4 vesicles, the respective processes of exo- and endocytosis appear to depart from this prediction. Therefore, one can conclude that while the overall dynamics of exo-and endocytosis of adipocytes is balanced by rosiglitazone pretreatment, the traffic of GLUT4-bearing vesicles appears to augment the membrane associated fraction of GLUT4. This could be achieved by many mechanisms, including the selective enhancement of exocytosis, a reduction of endocytosis or the combination of both.

The results of this study provide evidences that rosiglitazone may balance the insulininduced increase in the rate of exocytosis and endocytosis, which may prevent the insulininduced cell size increase.

\subsection{Pathophysiological Implications}

An insulin-dependent imbalance between the rates of exo- and endocytosis may promote the increase in cell size during lipogenesis. Consistent with this it was reported that vagally mediated insulin hypersecretion is associated with an increased adipocyte size and with insulin resistance (Del Prato et al., 1994; Jeanrenaud, 1978). While a net insulindependent increase of plasma membrane area recorded (Chowdhury et al., 2005; Velebit et al., 2008) is consistent with an increase in cell size mediated by insulin, it is presently not clear if and how an imbalance between exo- and endocytosis may induce insulin resistance. Activation of PPAR $\gamma$ in white adipose tissue increases the number of small adipocytes, and reduces the number of large adipocytes (Rangwala and Lazar, 2004). Small adipocytes are more sensitive to insulin (Lowell, 1999) and an increased number of small adipocytes in white adipose tissue can alleviate insulin resistance (Lowell, 1999). Present results suggest that rosiglitazone pretreatment not only increases the membrane turnover in adipocytes, but also balances out the insulin-mediated difference between the rates of exocytosis and endocytosis. This mechanism may prevent increase in cell size of adipocytes observed in 
pathophysiological conditions. Thus this may explain in part the role of rosiglitazone in alleviating insulin resistance symptoms. 


\section{Acknowledgements}

This work was supported by the Grant \#P3 310 of Slovenian Research Agency, the COST (European Cooperation in Science and Technology) action BM0602, and support from Ad Futura (Slovene Human Resources Development and Scholarship Fund). We thank for the generous sample of rosiglitazone to GlaxoSmithKline. 


\section{References}

Ahima, R.S., Flier, J.S., 2000. Adipose tissue as an endocrine organ. Trends Endocrinol.

Metab. 11, 327-332.

Auwerx, J., 1999. PPARgamma, the ultimate thrifty gene. Diabetol. 42, 1033-1049.

Betz, W.J., Mao, F., Smith, C.B., 1996. Imaging exocytosis and endocytosis. Curr. Opin. Neurobiol. 6, 365-371.

Bhatia, V., Viswanathan, P., 2006. Insulin resistance and PPAR insulin sensitizers. Curr. Opin. Investig. Drugs. 7, 891-897.

Blackmore, P.F., McPherson, R.K., Stevenson, R.W., 1993. Actions of the novel antidiabetic agent englitazone in rat hepatocytes. Metabolism 42, 1583-1587.

Bryant, N.J., Govers, R., James, D.E., 2002. The Measurement of GLUT4 Translocation in 3T3-L1 Adipocytes. Nat. Rev. Mol. Cell. Biol. 3, 267-277.

Chawla, A., Barak, Y., Nagy, L., Liao, D., Tontonoz, P., Evans, R.M., 2001. PPAR-gamma dependent and independent effects on macrophage-gene expression inlipid metabolism and inflammation. Nat. Med. 7, 48-52.

Chowdhury, H.H., Grilc, S., Zorec, R., 2005. Insulin induces a rapid increase in membrane area in single rat adipocytes. Adipocytes 1, 131-138.

Chowdhury, H.H., Kreft, M., Zorec, R., 2002. Rapid insulin-induced exocytosis in white rat adipocytes. Pflugers Arch. 445, 352-356.

Cochilla, A.J., Angleson, J.K., Betz, W.J., 1999. Monitoring secretory membrane with FM143 fluorescence. Annu. Rev. Neurosci. 22, 1-10.

Czech, M.P., 2002. Fat targets for insulin signaling. Mol. Cell. 9, 695-696.

Del Prato, S., Leonetti, F., Simonson, D.C., Sheehan, P., Matsuda, M., DeFronzo, R.A., 1994. Effect of sustained physiologic hyperinsulinaemia and hyperglycaemia on insulin secretion and insulin sensitivity in man. Diabetologia 37, 1025-1035. 
Di Guglielmo, G.M., Drake, P.G., Baass, P.C., Authier, F., Posner, B.I., Bergeron, J.J., 1998. Insulin receptor internalization and signaling. Mol. Cell. Biochem. 182, 59-63.

Ezaki, O., Kasuga, M., Akanuma, Y., Takata, K., Hirano, H., Fujita-Yamaguchi, Y., Kasahara, M., 1986. Recycling of the glucose transporter, the insulin receptor, and insulin in rat adipocytes. Effect of acidtropic agents. J. Biol. Chem. 261, 3295-3305.

Foster, L.J., Klip, A., 2000. Mechanism and regulation of GLUT-4 vesicle fusion in muscle and fat cells. Am. J. Physiol. 279, C877-C890.

Furnsinn, C., Brunmair, B., Meyer, M., Neschen, S., Furtmuller, R., Roden, M., Kühnle, H.F., Nowotny, P., Schneider, B., Waldhäusl, W., 1999. Chronic and acute effects of thiazolidinediones BM13.1258 and BM15.2054 on rat skeletal muscle glucose metabolism. Br. J. Pharmacol. 128, 1141-1148.

Henkel A.W., Lübke J., Betz W.J., 1996. FM1-43 dye ultrastructural localization in and release from frog motor nerve terminals. Proc Natl Acad Sci U S A. 93:1918-23.

Holman, G.D., Sandoval, I.V., 2001. Moving the insulin-regulated glucose transporter GLUT4 into and out of storage. Trends Cell. Biol. 11, 173-9.

Huang, J., Hsia, S.H., Imamura, T., Usui, I., Olefsky, J.M., 2004. Annexin II is a thiazolidinedione-responsive gene involved in insulin-induced glucose transporter isoform 4 translocation in 3T3-L1 adipocytes. Endocrinol. 145, 1579-1586.

Jeanrenaud, B., 1978. Hyperinsulinemia in obesity syndromes: its metabolic consequences and possible etiology. Metabolism 27, 1881-1892.

Johnson, J.A., Trasino, S.E., Ferrante, A.W. Jr., Vasselli, J.R., 2007. Prolonged decrease of adipocyte size after rosiglitazone treatment in high- and low-fat-fed rats. Obesity 15, 2653-2663. 
Kitagawa, K., Rosen, B.S., Spiegelman, B.M., Lienhard, G.E., Tanner, L.I., 1989. Insulin stimulates the acute release of adipsin from 3T3-L1 adipocytes. Biochim Biophys Acta. $1014,83-89$.

Lowell, B.B., 1999. PPARgamma: an essential regulator of adipogenesis and modulator of fat cell function. Cell 99, 239-242.

Martinez, L., Berenguer, M., Bruce, M.C., Le Marchand-Brustel, Y., Govers, R., 2010. Rosiglitazone increases cell surface GLUT4 levels in 3T3-L1 adipocytes through an enhancement of endosomal recycling. Biochem. Pharmacol. 79, 1300-1309.

Mudaliar, S., Henry, R.R., 2001. New oral therapies for type 2 diabetes mellitus: the glitazones or insulin sensitizers. Annu. Rev. Med. 52, 239-257.

Muretta, J.M., Romenskaia, I., Mastick, C.C., 2008. Insulin Releases Glut4 from Static Storage Compartments into Cycling Endosomes and Increases the Rate Constant for Glut4 Exocytosis. J. Biol. Chem. 283, 311-323.

Neves, G., Lagnado, L., 1999. The kinetics of exocytosis and endocytosis in the synaptic terminal of goldfish retinal bipolar cells. J. Physiol. (Lond) 515, 181-202.

Ntambi, J.M., Young-Cheul, K., 2000. Adipocyte differentiation and gene expression. J. Nutr. 130, S3122-S3126.

Oka, Y., Czech, M.P., 1984. Photo affinity labeling of insulin-sensitive hexose transporters in intact rat adipocytes. Direct evidence that latent transporters become exposed to the extracellular space in response to insulin. J. Biol. Chem. 259, 8125-8133

Okuno, A., Tamemoto, H., Tobe, K., Ueki, K., Mori, Y., Iwamoto, K., Umesono, K., Akanuma, Y., Fujiwara, T., Horikoshi, H., Yazaki, Y., Kadowaki, T., 1998. Troglitazone increases the number of small adipocytes without the change of white adipose tissue mass in obese Zucker rats. J. Clin. Invest. 101, 1354-1361. 
Olefsky, J.M., 2000. Treatment of insulin resistance with peroxisome proliferator-activated receptor gamma agonists. J. Clin. Invest. 106, 467-472.

Petersen, K.F., Shulman, G.I., 2002. Pathogenesis of skeletal muscle insulin resistance in type 2 diabetes mellitus. Am. J. Cardiol. 90, 11G-18G.

Phillips, L.S., Grunberger, G., Miller, E., Patwardhan, R., Rappaport, E.B., Salzman, A., 2001. Once- and twice-daily dosing with rosiglitazone improves glycemic control in patients with type 2 diabetes. Diab. Care. 24, 308-15.

Preininger, K., Stingl, H., Englisch, R., Furnsinn, C., Graf, J., Waldhausl, W., Roden, M., 1999. Acute troglitazone action in isolated perfused rat liver. Br. J. Pharmacol. 126, 372378.

Rangwala, S.M., Lazar, M.A., 2004. Peroxisome proliferator-activated receptor gamma in diabetes and metabolism. Review. Trends Pharmacol. Sci. 25, 331-336.

Rattarasarn, C., 2006. Physiological and pathophysiological regulation of regional adipose tissue in the development of insulin resistance and type 2 diabetes. Acta. Physiol. (Oxf) $186,87-101$.

Saltiel, A.R., Kahn, C.R., 2001. Insulin signalling and the regulation of glucose and lipid metabolism. Nature 414, 799-806.

Scherer, P.E., Williams, S., Fogliano, M., Baldini, G., Lodish, H.F., 1995. A novel serum protein similar to C1q, produced exclusively in adipocytes. J Biol Chem. 270, 26746-9.

Smith R.M., Charron M.J., Shah N., Lodish H.F., Jarett L., 1991. Immunoelectron microscopic demonstration of insulin-stimulated translocation of glucose transporters to the plasma membrane of isolated rat adipocytes and masking of the carboxyl-terminal epitope of intracellular GLUT4. Proc Natl Acad Sci U S A. 88:6893-7. 
Toledo, F.G, Sniderman, A.D., Kelley, D.E., 2006. Influence of hepatic steatosis (fatty liver) on severity and composition of dyslipidemia in type 2 diabetes. Diab. Care 29, 18451850.

Velebit, J., Kovačič, P.B., Prebil, M., Chowdhury, H.H., Grilc, S., Kreft, M., Jensen, J., Isenović, E.R., Zorec, R., 2008. Rosiglitazone modulates insulin-induced plasma membrane area changes in single 3T3-L1 adipocytes. J. Membr. Biol. 223, 141-149.

White, M.F., Kahn, C.R., 1994. The insulin signaling system. J. Biol. Chem. 269, 1-4.

Whitesell, R.R., Abumrad, N.A., 1985. Increased affinity predominates in insulin stimulation of glucose transport in the adipocyte. J. Biol. Chem. 260, 2894-2899.

Wu, Z., Xie, Y., Morrison, R.F., Bucher, N.L., Farmer, S.R., 1998. PPAR $\gamma$ induces the insulin-dependent glucose transporter GLUT4 in the absence of $\mathrm{C} / \mathrm{EBP} \gamma$ during the conversion of $3 \mathrm{~T} 3$ fibroblasts into adipocytes. J. Clin. Invest. 101, 22-32.

Zorzano A., Wilkinson W., Kotliar N., Thoidis G., Wadzinkski B.E., Ruoho A.E., Pilch P.F., 1989. Insulin-regulated glucose uptake in rat adipocytes is mediated by two transporter isoforms present in at least two vesicle populations. J. Biol. Chem. 264:12358-63. 


\section{Figure Legends:}

Figure 1. Immunocytochemical demonstration of the glucose transporter GLUT4 in

3T3-L1 adipocytes. (A) Representative light transmission images (upper panels) and immunofluorescence images labelled with anti-GLUT4 antibodies revealing the presence of GLUT4 (lower panel) in control cell (treated with vehicle, +Veh), in insulin-stimulated cells (+Ins), in rosiglitazone -pretreated cells (Rosi+Veh) and in Rosi-pretreated and Ins-stimulated cells (Rosi+Ins). Bars indicate $5 \mu \mathrm{m}$. (B) Mean ( \pm SEM) ratio of fluorescence intensity between the plasma membrane $(\mathrm{Im} ; 1.1 \mu \mathrm{m}$ wide ring around the plasma membrane; see explanation in Materials and Methods) and the cytoplasm (Ic). Numbers adjacent to error bars indicate numbers of cells analyzed. Asterisks indicate significant differences $(* * P<0.01$, *** $P<0.001 v s$. controls (Veh)). Note that all four images were taken with the same image acquisition parameter settings on the confocal microscope.

Figure 2. Time-dependent changes of FM1-43 fluorescence intensity reflecting cumulative exocytosis. (A) Single cross-section confocal micrographs of FM1-43 - stained adipocytes before (left panels) and at the end of recording (right panels) in control (vehicle addition, + Veh), in $0.2 \mu \mathrm{M}$ insulin-stimulated cells ( + Ins), in $10 \mu \mathrm{M}$ rosiglitazone-pretreated cells (Rosi+Veh) and in rosiglitazone-pretreated cells stimulated with insulin (Rosi+Ins). The fluorescence intensity is localized to the plasma membrane. Bars indicate $5 \mu \mathrm{m}$. The representative recordings of FM1-43 fluorescence intensity of respective experiments are shown on right. Arrows indicate the addition of agents as a bolus to reach indicated concentrations. (B) The average time-dependent changes in FM1-43 fluorescence intensity in (i) control cells where vehicle (open circles, $n=6$ ) or insulin (filled circles, $n=7$ ) was applied and (ii) in rosiglitazone-pretreated cells where vehicle (open squares, $n=6$ ) or insulin (filled 
squares, $n=6$ ) was applied. Error bars indicate standard error of mean. Arrows indicate the addition of vehicle and insulin, respectively. Asterisk indicate significant differences $\left({ }^{*} P<0.05,{ }^{* *} P<0.01\right.$ and ${ }^{* * *} P<0.001$ vs. Veh; ${ }^{\mathrm{a}} P<0.05$ Rosi + Ins $v s$. Ins $)$. Horizontal dotted lines indicate resting level at the time of insulin or vehicle addition. Regression lines (dotted lines; obtained using SPPS Sigma Plot software) are drawn according to the equations of the following forms: Mean intensity $[\%]=(1.8 \pm 0.1)[\% / \mathrm{min}] * \mathrm{t}[\mathrm{min}]+(95.2 \pm 0.7)[\%]$ for control $(+\mathrm{Veh})$; Mean intensity $[\%]=(7.3 \pm 0.15)[\% / \mathrm{min}] * \mathrm{t}[\mathrm{min}]+(82.1 \pm 3.1)[\%]$ for insulin-stimulated cells (Ins); Mean intensity $[\%]=(5.3 \pm 0.1)[\% / \mathrm{min}] * \mathrm{t}[\mathrm{min}]+(84.4 \pm$ 0.3) $[\%]$ for rosiglitazone-treated cells $($ Rosi+Veh) and Mean intensity [\%] $=(11.2 \pm 0.6)$ $[\% / \mathrm{min}] * \mathrm{t}[\mathrm{min}]+(71.1 \pm 3.6)[\%]$ for rosiglitazone-treated and insulin-stimulated cells (Rosi+Ins). The slope coefficients are significantly different from zero $(\mathrm{p}<0.001)$ and reflect the rate of cumulative exocytosis.

Figure 3. The measurement of parameters representing cumulative endocytosis. (A) The scheme of the procedure for determining cumulative endocytosis. Representative z-stack images obtained after the first and the second removal of FM1-43 from the recording medium (cell pretreated with rosiglitazone and then stimulated with insulin). Bar indicates $5 \mu \mathrm{m}$. Arrow indicates the addition of insulin (Ins) or vehicle (Veh). (B) Mean ( \pm SEM) residual fluorescence intensity (a.u.) of the interior of cells after first (black bars) and after second (white bars) removal of FM1-43 from the bathing medium. Asterisks indicate significant differences $(* P<0.05$ and $* * P<0.01$, paired t-test). (C) Histogram represents mean ( \pm SEM) relative increase of residual fluorescence intensity $(\% / \mathrm{min})$ after second removal of FM1-43 from the bathing medium, relative to the mean residual fluorescence intensity after the first removal of FM1-43. Numbers above columns indicate numbers of tested cells. Asterisks indicate significant differences $\left(* * P<0.01 v s\right.$. Veh, ${ }^{\text {aa }} P<0.01$ Rosi+Ins $v s$. Ins). 
Table 1. The rates of cumulative exocytosis and endocytosis in all experimental groups and comparison of fold changes vs. Control and vs. Ins measurements.

\begin{tabular}{|c|c|c|c|c|c|c|c|}
\hline & $\begin{array}{c}\text { Rate } \\
\text { Exo } \\
\text { (\%/min) }\end{array}$ & $\begin{array}{c}\text { Fold } \\
\text { change } v s . \\
\text { Cont } \\
\text { (Exo) } \\
\end{array}$ & $\begin{array}{c}\text { Fold } \\
\text { change } v s . \\
\text { Ins } \\
(\text { Exo) } \\
\end{array}$ & $\begin{array}{c}\text { Rate } \\
\text { Endo } \\
\text { (\%/min) }\end{array}$ & $\begin{array}{c}\text { Fold } \\
\text { change } \\
\text { vs. Cont } \\
\text { (Endo) } \\
\end{array}$ & 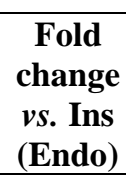 & $\begin{array}{c}\text { P } \\
\text { Exo } \\
\text { vs. Endo }\end{array}$ \\
\hline $\begin{array}{l}\text { Cont } \\
(+ \text { Veh })\end{array}$ & $\begin{array}{c}1.8 \pm 0.1 \\
n=6\end{array}$ & & & $\begin{array}{c}2.1 \pm 0.3 \\
n=7\end{array}$ & & & 0.85 \\
\hline+ Ins & $\begin{array}{c}7.3 \pm 0.5 \\
n=7\end{array}$ & 4.0 & & $\begin{array}{c}7.5 \pm 1.8 \\
\mathrm{n}=4\end{array}$ & 3.6 & & 0.73 \\
\hline Rosi + Veh & $\begin{array}{c}5.3 \pm 0.1 \\
\mathrm{n}=6\end{array}$ & 2.9 & & $\begin{array}{c}4.5 \pm 0.7 \\
\mathrm{n}=7\end{array}$ & 2.2 & & 0.44 \\
\hline Rosi + Ins & $\begin{array}{c}11.2 \pm 0.6 \\
\mathrm{n}=6\end{array}$ & 6.1 & 1.5 & $\begin{array}{c}13.3 \pm 1.6 \\
\mathrm{n}=4\end{array}$ & 6. & 1.8 & 0.54 \\
\hline
\end{tabular}


Figure 1
Click here to download high resolution image

A

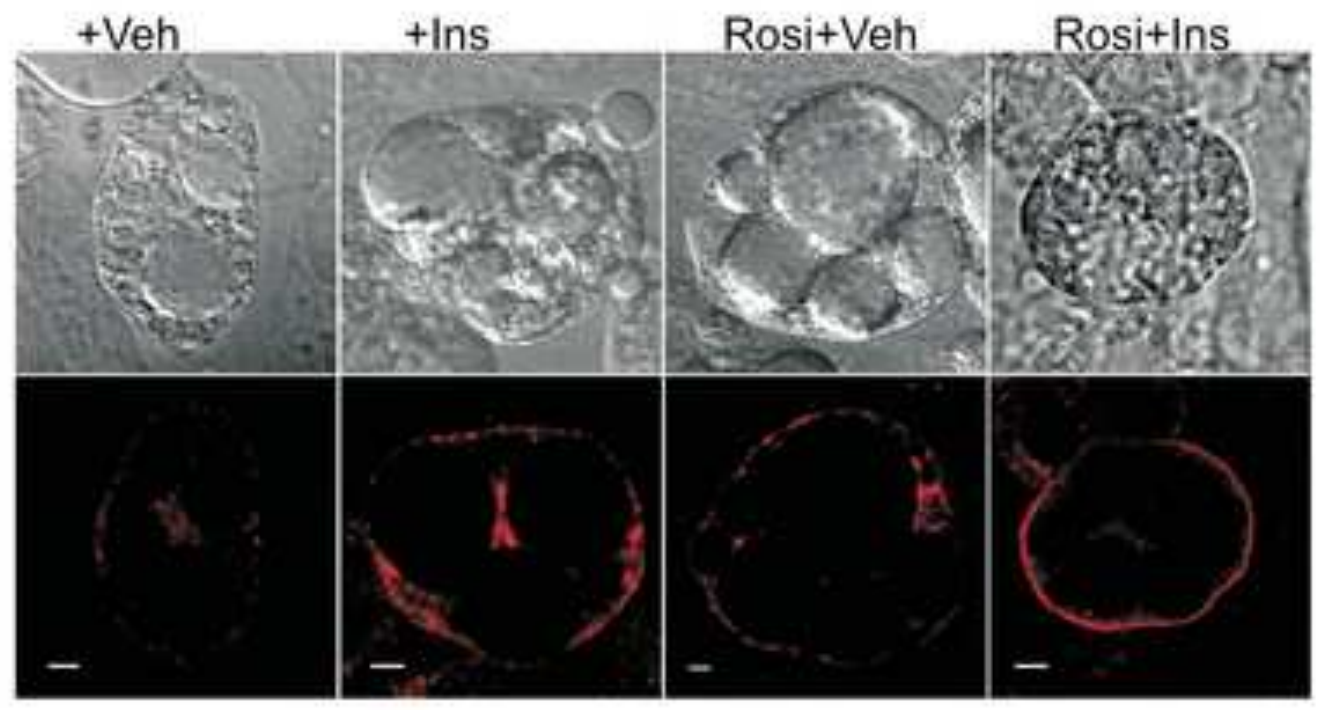

B

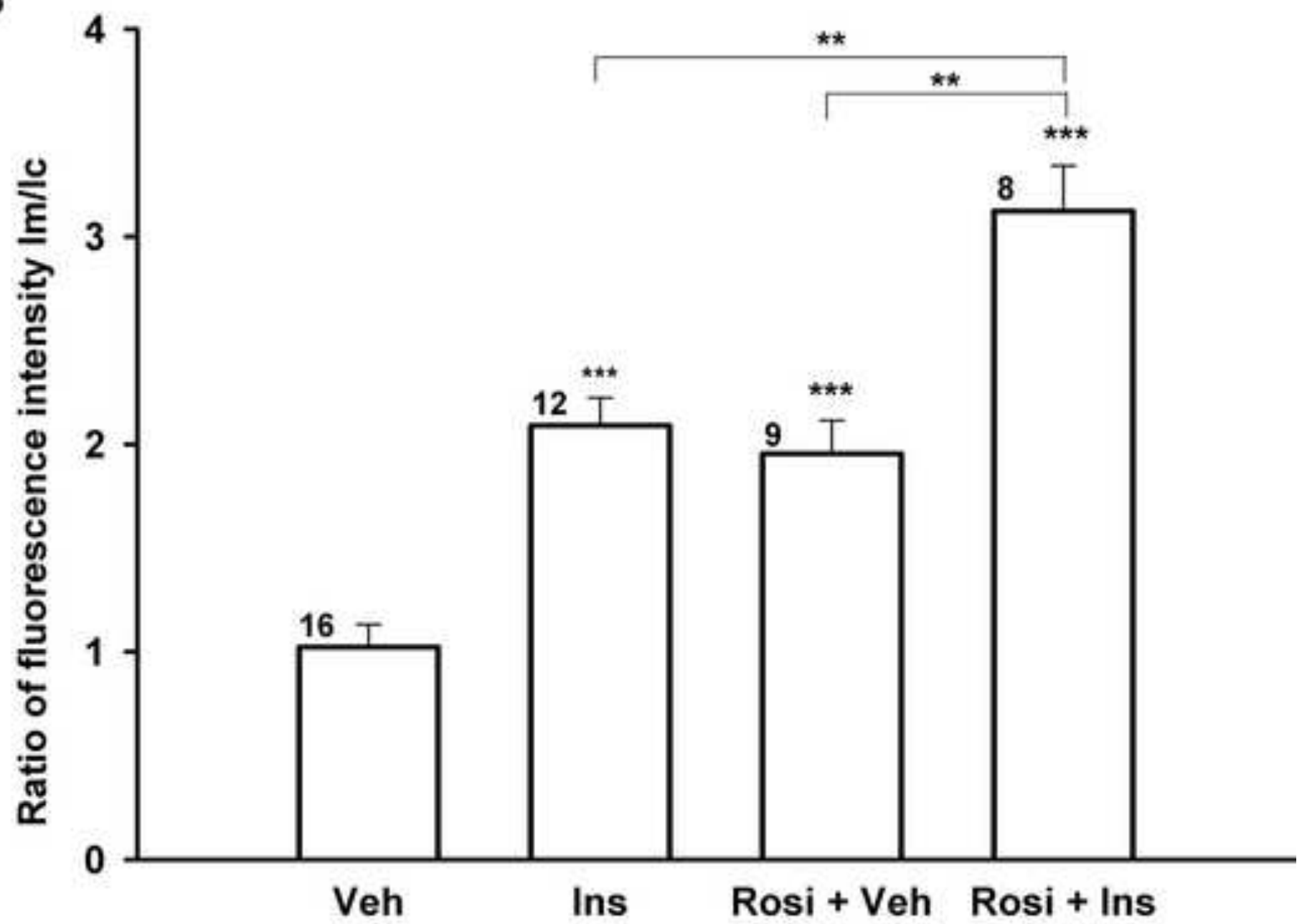


Figure 2
Click here to download high resolution image

A
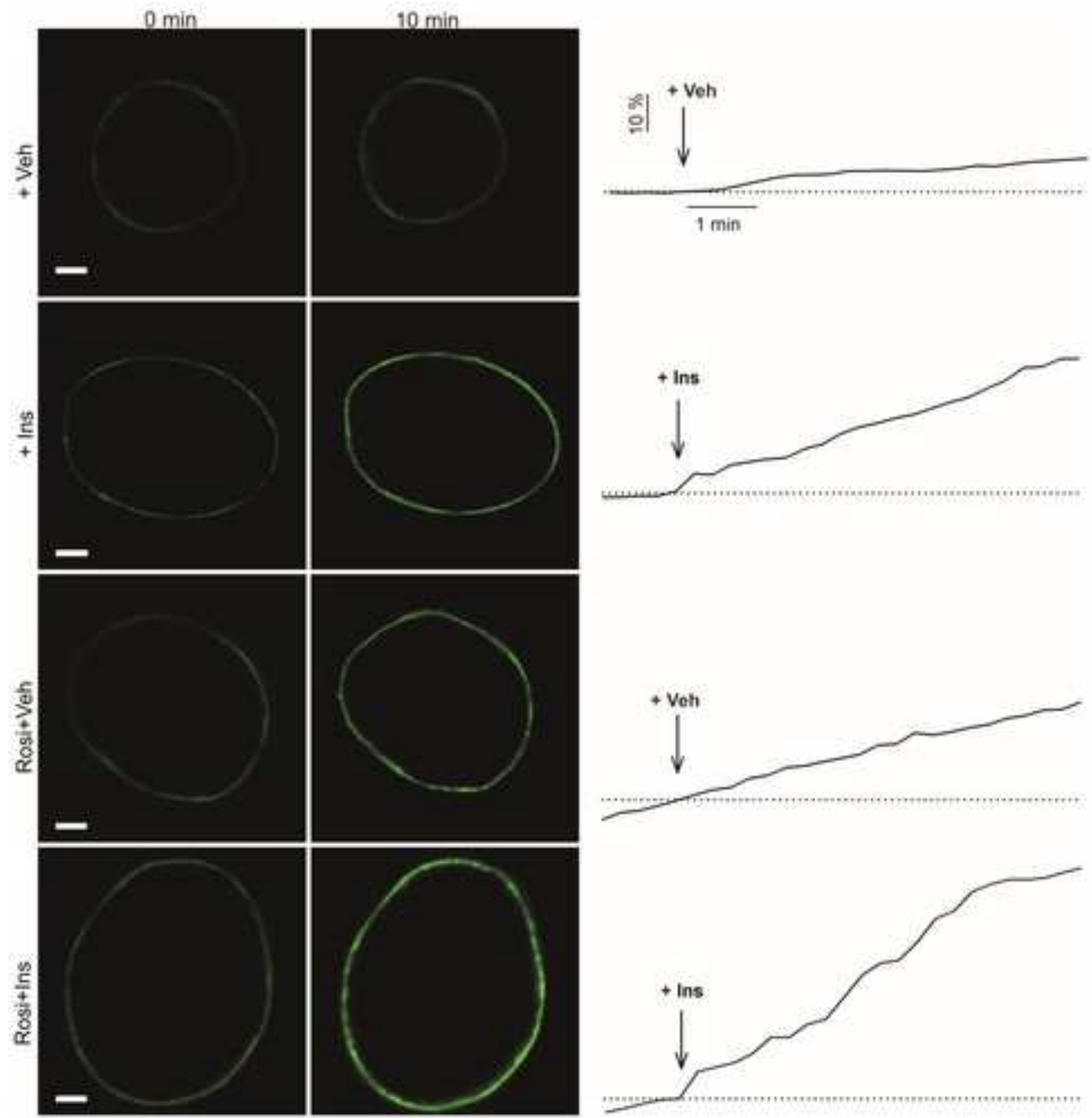

B
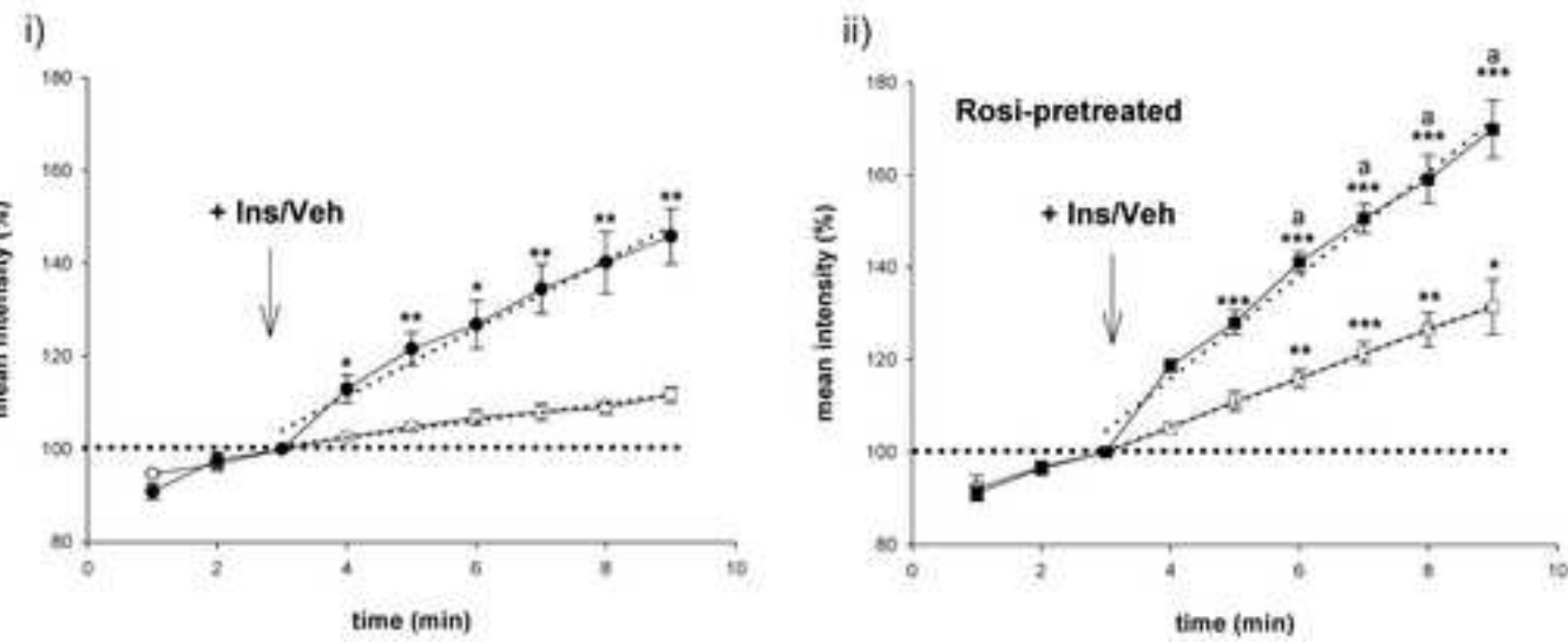
Figure 3

Click here to download high resolution image

A

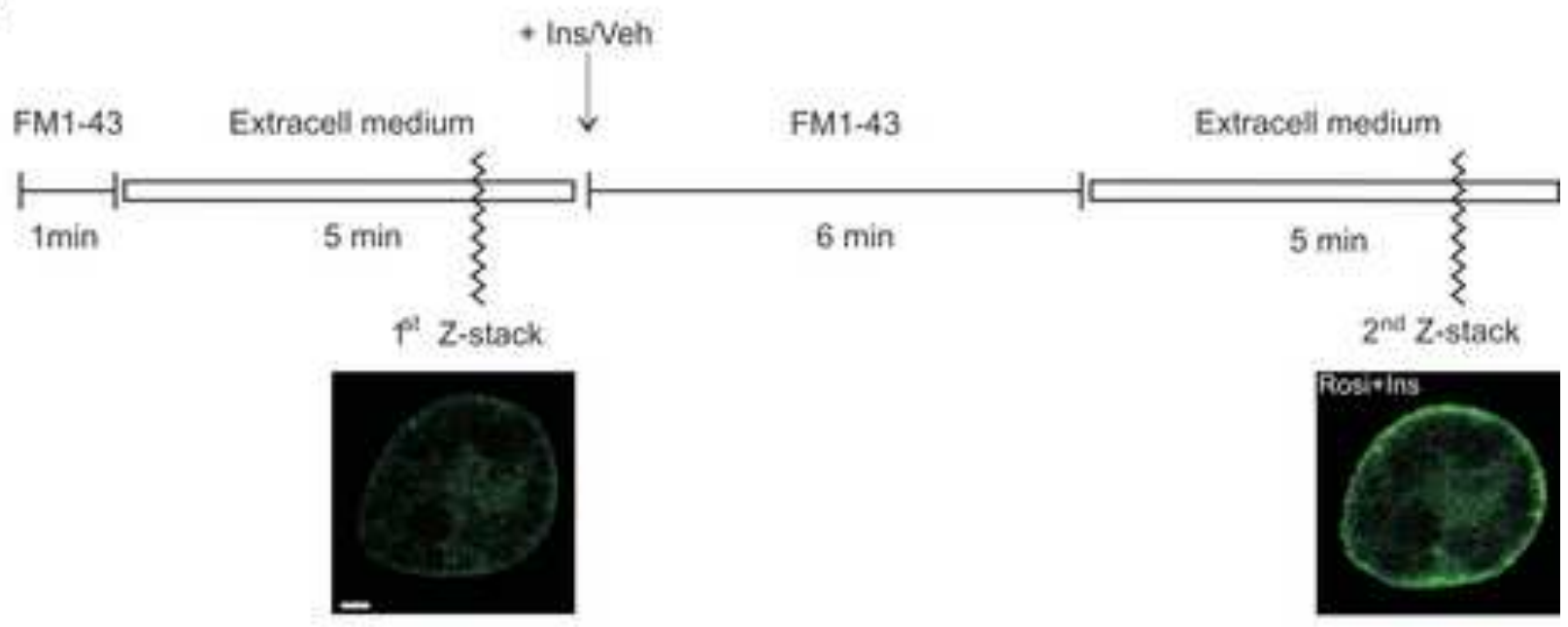

B

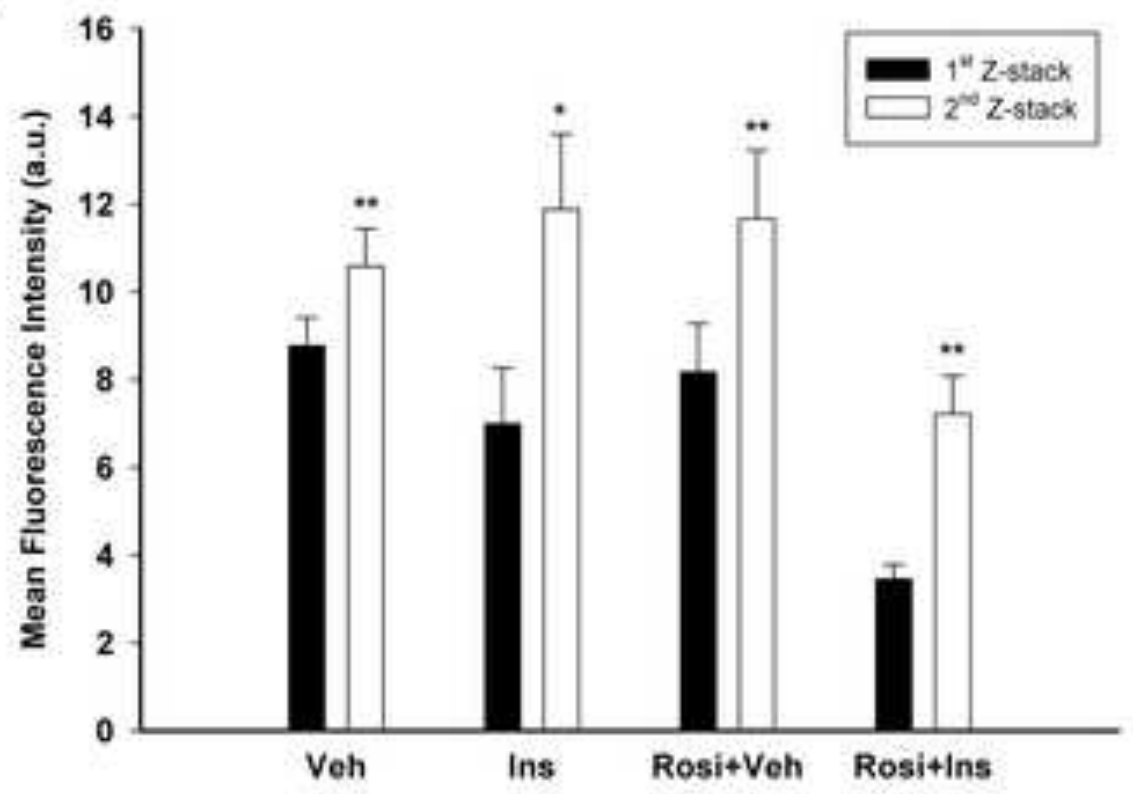

C

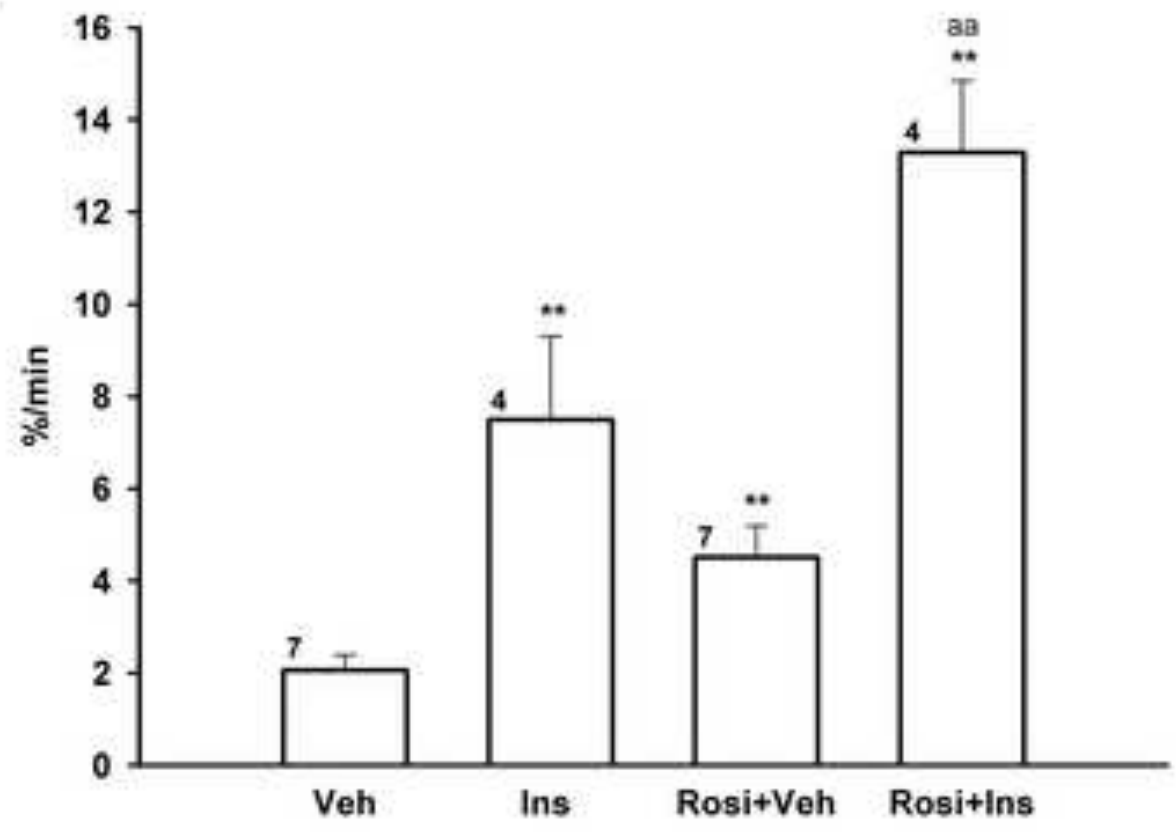

